\title{
Semantic interpretability does not influence masked priming effects
}

\begin{tabular}{|c|c|}
\hline Journal: & Quarterly Journal of Experimental Psychology \\
\hline Manuscript ID & QJE-STD-18-180.R1 \\
\hline Manuscript Type: & Standard Article \\
\hline $\begin{array}{l}\text { Date Submitted by the } \\
\text { Author: }\end{array}$ & 20-Nov-2019 \\
\hline Complete List of Authors: & $\begin{array}{l}\text { Tseng, Hayley; University of Bristol, School of Experimental Psychology } \\
\text { Lindsay, Shane; University of Hull, } \\
\text { Davis, Colin; University of Bristol, School of Experimental Psychology }\end{array}$ \\
\hline Keywords: & $\begin{array}{l}\text { semantic interpretability, masked priming, morphological processing, } \\
\text { visual word recognition, lexical decision }\end{array}$ \\
\hline
\end{tabular}

\section{SCHOLARONE ${ }^{\text {M }}$ \\ Manuscripts}


Semantic interpretability does not influence masked priming effects

Hayley Tseng ${ }^{1}$, Shane Lindsay ${ }^{2}$, \& Colin J. Davis ${ }^{1}$

${ }^{1}$ University of Bristol

2 University of Hull

\author{
Author note \\ Hayley Tseng, School of Psychological Science, University of Bristol. Shane Lindsay, \\ Department of Psychology, University of Hull. Colin J. Davis, School of Psychological Science, \\ University of Bristol. Sine Bakumeni and Hannah Barnett assisted with data collection at the \\ University of Hull.
}


Correspondence concerning this article should be addressed to Colin J. Davis, School of Psychological Science, University of Bristol, 12A Priory Road, Clifton, Bristol, UK, BS8 1TU. E-mail: pscjd@bristol.ac.uk 


\begin{abstract}
Much of the recent masked nonword priming literature demonstrates no difference in priming between affixed and non-affixed nonword primes (e.g., maskity-MASK vs maskond$M A S K)$. A possible explanation for the absence of a difference is that studies have used affixed primes which were semantically uninterpretable (Heathcote, Nation, Castles, \& Beyersmann, 2017). Therefore, this explanation indicates semantic interpretability plays a fundamental role in masked priming. To test this account, we conducted an experiment using the masked priming paradigm in the lexical decision task. We compared responses to targets which were preceded by one of four primes types: 1) interpretable affixed nonwords (e.g. maskless-MASK), 2) uninterpretable affixed nonwords (e.g. maskity-MASK), 3) non-affixed nonwords (e.g., maskond$M A S K)$ and 4) unrelated words (e.g. tubeful-MASK). Our results follow the trend of finding no difference between affixed and non-affixed primes. Critically, however, we observed no difference in priming between uninterpretable and interpretable affixed primes. Thus, our results suggest that semantic interpretability does not influence masked priming.
\end{abstract}

Keywords: semantic interpretability, masked priming, morphological processing, visual word recognition, lexical decision 


\section{Semantic interpretability does not influence masked priming effects}

The role of morphological processing in the visual identification of complex words has been the subject of intensive study by psycholinguists. Morphemes are the building blocks of language, and the ability to recognise, analyse and combine morphemes is critical for comprehension and production in skilled language use. For example, in order to understand a new word like unfriend we need to be able to identify its component morphemes. Evidence suggests that this process of decomposing a word into its morphemes continues to be important even after the word has become familiar in its whole word form (see Rastle \& Davis, 2008 for a review). Thus, research over the last couple of decades has focussed on questions relating to how and when decomposition occurs. What information do readers make use of to decompose a complex word into its morphemic constituents, and does this occur before or after the lexical representation of the word is accessed?

\section{Masked priming with word primes}

A popular technique for investigating these issues is masked priming (e.g., Crepaldi, Hemsworth, Davis, \& Rastle, 2016; K. I. Forster, Davis, Schoknecht, \& Carter, 1987; Frost, Forster, \& Deutsch, 1997; Grainger, Colé, \& Segui, 1991; W. Marslen-Wilson, Tyler, Waksler, \& Older, 1994; Rastle, Davis, Marslen-Wilson, \& Tyler, 2000). For example, participants can respond (e.g., by making a lexical decision) more rapidly to a target word like $R E A D$ when it is preceded by a brief $(\sim 50 \mathrm{~ms})$ presentation of a related morphologically complex word like reader than when it is preceded by a unrelated control word. Critically, this priming effect is greater than would be expected on the basis of semantic or orthographic information (e.g., Drews \& Zwitserlood, 1995; Rastle et al., 2000). For example, Rastle et al. (2000) found that priming was 
greater for morphologically related prime-target pairs like vagueness-VAGUE than for primetarget pairs like electrode-ELECT, where there is equal orthographic overlap but no morphological relationship. Such priming effects have been interpreted as evidence of an early process that rapidly decomposes a prime into its morphemes, facilitating identification of the morpheme shared by prime and target.

Further evidence concerning the nature of this early decomposition process was provided by experiments reported by Longtin, Segui, and Hallé (2003) and Rastle, Davis, and New (2004), who investigated the effect of pseudoaffixed word primes like corner, which have the orthographic appearance of affixed forms, but have no genuine morphological or semantic relationship to the target (i.e., a corner is not one who corns). These researchers found that masked priming effects for corner-CORN were just as great as for transparently related pairs like darkness-DARK, and significantly greater than for orthographic control primes like brothelBROTH (where $-e l$ is not an English affix). Rastle and Davis (2008) concluded that this early decomposition process is based entirely on orthography and is blind to semantics. In addition to these initial investigations in French and English, similar results have been reported in Dutch (Diependaele, Sandra, \& Grainger, 2005), Hebrew (Frost et al., 1997), Spanish and Basque (Duñabeitia, Perea, \& Carreiras, 2007) and Russian (Heyer \& Kornishova, 2018; Kazanina, 2011).

Although some studies have reported significantly greater priming for transparent than for opaque primes (e.g., Diependaele et al., 2005; Feldman et al., 2015), these empirical differences can probably be attributed to methodological differences (see Davis \& Rastle, 2010). In particular, the difference between transparent and opaque primes is modulated by prime duration: When there is sufficient time for semantic processing to occur, priming is not observed for 
opaque forms. There is still some uncertainty concerning what constitutes sufficient time, but a reasonable estimate is $60 \mathrm{~ms}$ (in the masked priming paradigm, primes that are presented for longer than this duration are often consciously perceived, though of course this need not imply that conscious awareness is a critical factor). Indeed, Heyer and Kornishova (2018) investigated whether the difference in priming effect size between opaque and transparent primes would emerge regardless of prime duration. A significant difference between opaque and transparent primes appeared for trials involving a long prime duration $(77 \mathrm{~ms})$. However, this difference did not occur for trials involving a short prime duration (39 ms). Currently, the general consensus in the literature is that a difference between transparent and opaque primes is likely to be observed for primes that are presented for durations longer than $60 \mathrm{~ms}$ (e.g., Diependaele et al. (2005); Rastle et al. (2000); Feldman et al. (2015)), whereas a difference is unlikely to reported for primes that are presented for durations less than $50 \mathrm{~ms}$ (see Davis \& Rastle, 2010 for a metaanalysis).

There are a minority of studies which demonstrate semantic transparency effects with prime durations of 50ms (e.g. Morris, Frank, Grainger, \& Holcomb, 2007). However, this discrepancy in findings could again be attributed to methodological differences (Davis \& Rastle, 2010). For example, while most studies which have reported no difference in priming between opaque and transparent primes used forward masking (e.g. Gold and Rastle, 2007; Kazanina, Dukova-Zheleva, Geber, Kharlamov, \& Tonciulescu, 2008), studies like Morris et al (2007) used backward masking. In summary, a large body of evidence has been amassed to support the notion of an early morpho-orthographic decomposition process that is blind to semantics (and hence unaffected by semantic transparency). In summary, a large body of evidence has been amassed to 
support the notion of an early morpho-orthographic decomposition process that is blind to semantics (and hence unaffected by semantic transparency).

\section{Masked priming with nonword primes}

A common variation of the masked morphological priming paradigm uses nonwords as primes (e.g., Beyersmann, Casalis, Ziegler, \& Grainger, 2015, Beyersmann, Cavalli, Casalis, and Colé, 2016); Heathcote et al., 2017; Longtin \& Meunier, 2005; McCormick, Brysbaert, \& Rastle, 2009; McCormick, Rastle, \& Davis, 2009; Morris, Porter, Grainger, \& Holcomb, 2011). From a methodological standpoint, the use of nonwords has some advantages. In particular, using nonwords as primes makes it much easier to compare different prime conditions with the same targets (morphological priming experiments with word primes usually require comparisons across different word targets). Furthermore, it is potentially advantageous to use primes that are not nonwords so as to minimise lexical influences (of words other than the target) on priming. It is well-established that masked word form primes can give rise to inhibitory priming effects; for example, a prime like rocket may result in slower lexical decision latencies to the target ROCK, relative to an unrelated word prime (e.g., Davis \& Lupker, 2006; De Moor \& Brysbaert, 2000; Segui \& Grainger, 1990). This inhibitory priming effect may reflect competition between the lexical representations of the prime and the target. By contrast, inhibitory priming effects are not usually observed for nonword primes.

If letter strings containing (pseudo-)affixes automatically engage a morpho-orthographic decomposition mechanism, it is reasonable to expect that nonword primes formed by combining stems with affixes should give rise to similar priming effects as those observed with word primes (e.g., worder-WORD should give similar priming effects to corner-CORN or burner-BURN). Such results have indeed been observed. For example, McCormick et al. (2009) found that 
priming for nonword primes like alarmer-ALARM was statistically equivalent to that obtained for word primes like national-NATION and notional-NOTION (high and low frequency word primes, respectively). They interpreted this result as "lending strong support to the notion of a routine form of decomposition that is applied to all morphologically structured stimuli" (McCormick et al., 2009, p. 1706).

However, caution is required when interpreting priming effects obtained with morphologically complex nonword primes. A natural question to ask about such effects is whether they might more parsimoniously be interpreted as reflecting purely orthographic, as opposed to morpho-orthographic processing. After all, very similar priming effects are obtained in orthographic form priming experiments in which there is no reason to suppose morphological involvement. For example, Lupker, Zhang, Perry, and Davis (2015) examined the effect of adding a consonant at the beginning or end of a word (e.g., zjudge-JUDGE or judgez-JUDGE) and observed priming effects of greater than $30 \mathrm{~ms}$. Note that such form priming effects do not depend on preserving the contiguity of the target letters. For example, Grainger and colleagues (Van Assche \& Grainger, 2006; Welvaert, Farioli, \& Grainger, 2008) have shown large priming effects for primes in which non-target letters are inserted within the word (e.g., musxtayrdMUSTARD). The Form Priming Project (FPP; Adelman et al., 2014), a large-scale masked priming experiment in which over 1000 participants were tested across 14 sites, found a $19 \mathrm{~ms}$ priming effect for primes formed by inserting two random (non-repeat) letters within the target word (e.g., desaxign-DESIGN). Related results on the perceptual similarity of orthographic neighbours formed by letter addition/deletion have been observed in unprimed lexical decision (Davis \& Taft, 2005; Davis, Perea, \& Acha, 2009), eye-tracking (Davis et al., 2009), and semantic categorisation (Bowers, Davis, \& Hanley, 2005). For example, Bowers et al. (2005) 
found that participants took longer (and were less accurate) to reject the word apex (which has the deletion neighbour ape) as a type of animal than to reject apex as a type of vehicle (and conversely scar took longer to reject as a type of vehicle than as a type of animal). The implication is that deletion neighbours are processed to the level of meaning, such that performance is impaired when these neighbours would require a different response than the word that was presented. It is important to emphasise that these empirical findings provided confirmations of the predictions made by a computational model of orthographic processing (Davis, 1999, 2010); the orthographic similarity of addition/deletion neighbours is also predicted by other models of orthographic processing (e.g., Adelman, 2011; Grainger, Van Heuven, \& Bonin, 2003; Norris, Kinoshita, \& Casteren, 2010; Whitney, 2001). In summary, finding that alarmer-ALARM results in priming relative to an unrelated prime cannot be interpreted as evidence for a morphological process, because such priming effects are predicted by models that include no morphological processing.

One approach to attempt to establish that priming effects with complex nonword primes do entail morphological processing would be to show that stronger priming is obtained for (pseudo-)affixed nonword primes like alarmer than for non-affixed nonword primes like alarmel, where form overlap is matched. Some experiments have reported such a difference (e.g., Longtin \& Meunier, 2005; McCormick et al., 2009). However, in these experiments the relevant comparisons involved different targets and/or participants, which is not ideal. Furthermore, the priming effects for non-affixed nonword primes did not attain significance in these experiments, which is inconsistent with the usual pattern for orthographic form primes (e.g., Adelman et al., 2014). By contrast, more recent investigations using within-item designs have tended to find equivalent priming for non-interpretable affixed and non-affixed nonword primes (e.g., 
Beyersmann et al., 2015, 2016; Morris et al., 2011). Faced with these null effects, the most straightforward conclusion would appear to be that the priming effects obtained with morphologically complex nonword primes are driven entirely by form overlap, with no need to posit any role for morphological decomposition or other morphological processing.

\section{Does semantic interpretability influence nonword priming?}

However, an alternative interpretation of these data, recently suggested by Heathcote et al. (2017), is that the above-cited studies failed to find a difference in priming between affixed and non-affixed nonwords because the affixed nonwords were semantically noninterpretable. In support of this interpretation, Heathcote et al. (2017) reported a lexical decision experiment in which affixed nonword primes that had been rated as semantically plausible resulted in significantly greater priming than non-affixed control primes; for example, cheapize-CHEAP resulted in greater priming than cheapstry-CHEAP. As they note, "The obvious advantage of interpretable relative to non-interpretable complex novel words is that interpretable stem-affix combinations generate meaning, whereas non-interpretable stem-affix combinations do not".

Evidently readers are able to determine whether a novel affixed form is interpretable. Faced with a novel word like cheapize, skilled readers are able to determine a likely morphological structure and then use this to come up with a possible interpretation (e.g., "to make cheap"). In particular, Heathcote et al. (2017) appealed to the notion of a licensing mechanism governing the (re-)combination of stems and affixes (Schreuder \& Baayen, 1995). This mechanism succeeds for interpretable primes like cheapize but is unsuccessful for uninterpretable and non-affixed primes, resulting in reduced priming effects. Potentially, then, the mixed empirical findings may reflect differences in the proportion of interpretable primes (or degree of prime interpretability) in different experiments. 
As Heathcote et al. (2017) note, there are previous observations that provide support for the role of interpretability. Most relevantly, Meunier and Longtin (2007) found that morphologically complex pseudowords were effective primes of their stems in cross-modal priming, but only if the pseudoword was interpretable. That is, priming was found for rapidifierRAPIDE (an English equivalent is quickify-QUICK), but not for sportation-SPORT. They concluded that "semantic interpretability plays a major role during pseudoword recognition" (p. 467). Other evidence for the role of interpretability (and support for a licensing mechanism) comes from studies that have found that interpretable morphologically complex nonwords take longer to reject in a lexical decision task than uninterpretable controls (Burani, Dovetto, Spuntarelli, \& Thornton, 1999; Coolen, Van Jaarsveld, \& Schreuder, 1991; Wurm, 2000).

Nevertheless, the latter studies were not masked priming experiments, and do not challenge the claim that early processing involves a semantically-blind orthographic parser. Indeed, as outlined earlier, masked priming experiments showing the absence of semantic transparency effects with word primes have led to an explanatory framework in which semantic processing does not begin until later (Heyer \& Kornishova, 2018; Rastle \& Davis, 2008) ${ }^{1}$. This

\footnotetext{
${ }^{1}$ Semantic interpretability and semantic transparency are overlapping, though not perfectly equivalent concepts. In the same way that nonwords cannot be said to be "regular" or "irregular" (because they do not have a correct pronunciation), nonwords cannot be said to be semantically "transparent" or "opaque", given that their meaning is not defined. Nevertheless, it is legitimate to speak of the semantic interpretability of a nonword, i.e., how readily readers are able to determine a possible meaning of that nonword, based on its constituent morphemes. A related
} 
time-course is consistent with semantic priming experiments: semantic/associative priming effects only start to become robust for primes that are presented for around $80 \mathrm{~ms}$ (for a metaanalysis, see Brysbaert, McCormick, Van der Haegen, Keuleers, \& Davis, 2015). A relatively deep level of semantic processing is required to determine that cheapize is interpretable, perhaps more than one might expect could be afforded a masked prime. Thus, while interpretability is undoubtedly a factor that influences processing of nonwords, stronger evidence is required to support the claim that this factor exerts its influence sufficiently rapidly to provide an explanation of differences in masked form priming effects for different nonword primes.

Furthermore, the claim that interpretability influences priming effects for masked nonword primes is inconsistent with a previous examination of this issue. Longtin and Meunier (2005) found equivalent priming from interpretable (rapidifier-RAPIDE) and non-interpretable (sportation-SPORT) nonword primes. However, as noted earlier, these authors found no priming for nonword primes with non-affixed endings (rapiduit-RAPIDE). Evidently the available literature provides a somewhat mixed picture. Longtin and Meunier (2005)'s result raises the possibility that the difference between interpretable and non-affixed primes observed by Heathcote et al. (2017) could reflect the presence of an affix, rather than the interpretability of the stem-affix combination. Indeed, Heathcote et al. (2017)'s experiment appears to be lacking the full set of conditions required to support any conclusion regarding prime interpretability.

\footnotetext{
term is semantic plausibility, which is sometimes used by Heathcote et al. (2017); here we treat "semantic plausibility" as synonymous with "semantic interpretability".
} 
In view of these considerations, a replication of Heathcote et al. (2017) was warranted. We took a few steps to achieve a higher level of power than their original experiment: a) we greatly increased the size of the stimulus set, b) we tested a relatively large number of participants, and c) given that Heathcote et al. (2017) found that (numerically at least) the difference between the interpretable affixed and (non-interpretable) non-affixed conditions was greater for suffixes than for prefixes we decided to focus our power by restricting our attention to suffixes. Critically, we added a new prime condition comprising uninterpretable affixed nonwords, i.e., nonwords formed by stem-affix combinations that are not readily interpretable (e.g., maskity). If the difference reported by Heathcote et al. (2017) is a genuine interpretability effect there should be greater priming for prime-target pairs like maskless-MASK than for pairs like maskity-MASK. . If our findings do support Heathcote et al (2017), then our study would be inconsistent with the trend in the literature reporting lack of semantic transparency effects during early processing.

\section{Method}

\section{Participants}

There were 122 participants in total. Of these, 73 participants were tested at the University of Bristol and 49 at the University of Hull. At both sites the participants were psychology undergraduates who participated in exchange for course credit; all had normal or corrected-tonormal vision. The study was approved by the University of Bristol Faculty of Science Research Ethics Committee and the University of Hull Faculty of Health Sciences Ethics Committee, and all participants provided their informed consent. 


\section{Stimuli and Design}

The experiment used a within-subjects design in which the independent variable was

Prime Type and the dependent variables were reaction time and accuracy. The four prime types were: a) interpretable affixed nonwords, b) uninterpretable affixed nonwords, c) nonaffixed nonwords, and d) unrelated primes. A Latin square design was used to rotate the prime stimuli across targets, resulting in four counterbalanced lists. There were 208 target stimuli, half of which were real words. Three-eighths of the target stimuli were drawn from Heathcote et al. (2017)'s items, to which we added a further 130 stimuli. The target words were all monomorphemic, ranging in frequency from 0.6 to 510 per million $($ mean $=87.7, \mathrm{SD}=112.4)$, and in length from 3 to 7 letters $($ mean $=4.8, \mathrm{SD}=0.9)$. Each of the target words was a stem morpheme in at least one polymorphemic English word (for example, round is the stem of the word roundness). Related primes were formed by adding an affix or a non-affix letter string to these stems. Following Heathcote et al. (2017), no orthographic alterations were made to stems when adding suffixes (e.g., final $e$ was not dropped when adding an initial-vowel suffix).

Interpretable primes were created by combining each stem with a suffix to form a semantically plausible nonword (e.g., the suffix -less was added to the stem mask to generate the nonword maskless). In the case of target stimuli drawn from Heathcote et al. (2017), we used the same primes as in their experiment. For the new targets we obtained subjective evaluations of the plausibility of multiple candidate suffixed forms from a small group of native speakers (mostly undergraduates), who rated plausibility on a scale from 1 (not plausible) to 5 (very plausible). Interpretable affixed nonwords were judged as plausible (at least 3 out of 5) by at least half of the raters. Uninterpretable nonwords (e.g., maskity) were created in the same way as interpretable 
primes, except that the resulting affixed nonword was rated as implausible by at least half of the raters.

Non-affixed nonword primes were created by combining stems with a string of letters which were not suffixes (e.g., ort, lem). We attempted to minimise orthographic overlap between the stem and letter string endings, although some overlap could not be avoided. The unrelated prime condition comprised affixed words that shared no more than two letters with their corresponding targets (e.g., prideful-ACID). Stimulus characteristics for the primes paired with word targets are shown in Table 1.

\section{--- Insert Table 1 about here ---}

Pronounceable nonword stimuli were created by changing one or two letters of corresponding word targets. Primes were constructed by applying the same changes to the corresponding related primes. For example, the nonword target MISK was constructed by changing the $a$ in MASK to an $i$, and the related primes then became miskless, miskity and miskond. The same unrelated primes were used for the corresponding word targets (e.g., the word target MASK and the nonword target MISK were both preceded by the unrelated prime tubeful). Items were counterbalanced so that a participant would not see a word and a nonword target it was derived from (i.e., they wouldn't see $M A S K$ and $M I S K$ ). The full set of stimuli for this experiment, as well as the raw data, can be found at https://osf.io/7y2ve/.

\section{Procedure}

Participants were seated approximately $60 \mathrm{~cm}$ in front of a monitor attached to a PC running Microsoft Windows 7. DMDX software (K. I. Forster \& Forster, 2003) was used to present the stimuli and record the reaction time and accuracy of responses. Each trial began with 
a forward mask (\#\#\#\#\#\#\#\#\#) that was displayed for $500 \mathrm{~ms}$ in the centre of the screen. The prime was then presented in lower case for approximately $50 \mathrm{~ms}$, followed by the target which was presented in upper case until the participant responded (or until the trial timed out after 2 seconds). All stimuli were presented in white Courier New font on a black background. Primes were presented in 12 point font; the size of the target and mask stimuli was $50 \%$ greater (i.e., 18 point). Participants were instructed to decide whether each stimulus was a word or nonword as fast as possible without making too many errors. They used the left and right control keys to make nonword and word responses respectively. Feedback (the word "Wrong") was given on trials to which partipants made incorrect responses or failed to respond within $2500 \mathrm{~ms}$. The experiment proper was preceded by eight practice trials. This part of the experiment took between 10 and 15 minutes.

Immediately following the lexical decision task, participants made ratings of the semantic plausibility of 52 nonwords, which were presented one at a time on the screen. These nonwords corresponded to the affixed primes that had been presented to that participant, preceding word targets, although there was no mention of any relationship between the two parts of the experiment. As in the pre-test, participants indicated the plausibility of each nonword on a scale of 1 to 5 ( 1 being not plausible and 5 being very plausible). This part of the experiment took around five minutes.

\section{Data analysis}

We used R (Version 3.5.1; R Core Team, 2018) and the R-packages BayesFactor (Version 0.9.12.4.2; Morey \& Rouder, 2018), bindrcpp (Version 0.2.2; Müller, 2018), coda (Version 0.19.1; Plummer, Best, Cowles, \& Vines, 2006), dplyr (Version 0.7.6; Wickham, Francois, Henry, \& Müller, 2017), ez (Version 4.4.0; Lawrence, 2016), ggplot2 (Version 3.0.0; Wickham, 


\section{Interpretability ratings}

\section{Results}

--- Insert Figure 1 about here ---

Each of the affixed nonwords was rated by at least 30 participants. A response key other than digits 1 through 5 was recorded for $0.8 \%$ of the ratings, and these responses were discarded; for the remaining responses the median rating was 3 and the modal rating was 1 . The most interpretable nonword was "maskless" (given a rating of 5 by $83 \%$ of raters) and the least interpretable nonword was "happyation" (given a rating of 1 by $71 \%$ of raters, and a rating of 2 by a further $26 \%$ ). An interpretability score was computed for each nonword based on its mean rating; these scores can be found at https://osf.io/7y $2 \mathrm{ve} /$.

In general, the preliminary assignment of nonwords to interpretability conditions was supported, such that the interpretable condition was associated with significantly higher scores than the uninterpretable condition, Welch's $t(177.37)=17.43, p<.001$. However, there was some overlap between the conditions, which was mostly due to nonwords that we had originally assigned as interpretable, but which were rated as relatively uninterpretable by participants (this included several items of our construction, e.g., "scarfness", "musicize", but also several of Heathcote et al. (2017)'s items, e.g., "bulber", "cheapize"). In addition, there were five nonwords that we had assigned to the uninterpretable condition that participants rated as relatively 
interpretable (e.g., "stuntness", "breakism"). To ensure a clear separation of the two interpretability conditions, we used the median interpretability score plus or minus 0.05 to form cutoffs, excluding from further analysis any "interpretable" nonwords with scores of less than 2.65, and any "uninterpretable" nonwords with scores of more than 2.55. Also, nonwords whose ratings did not support their initial classification were re-assigned to the other condition if the ratings met the other condition's criterion for inclusion. For example, if a nonword originally assigned as "interpretable" was rated as "uninterpretable", then the nonword would be reclassified as "uninterpretable". The exclusion of target words in which one or both of the associated affixed nonwords did not satisfy this criterion resulted in the elimination of 28 items, leaving us with 76 target words. Of the excluded items, 11 were from Heathcote et al. (2017)'s stimuli. Figure 1 presents histograms of interpretability scores for the two nonword conditions following item exclusions.

\section{Lexical decision data \\ Data Cleaning}

Targets for which one or both nonword primes failed to satisfy the above rating criteria were treated as fillers, and were not included in the analysis of lexical decision data. Initial inspection of these data revealed one word target that was associated with a high error rate (greater than 2.5 SDs more than the mean). This target (FRILL) was excluded from further analysis. The same criterion led to the exclusion of four nonwords. The resulting set of target stimuli comprised 75 words and 98 nonwords.

Median accuracy across participants was $93.64 \%$, and all but one participant had mean accuracies of greater than $75 \%$ correct; this error-prone participant was excluded from further 
analysis, as was one participant whose mean RT was more than 3 SDs slower than the mean. Following these exclusions there were 30 participants for each of the four counterbalanced versions of the experiment.

Erroneous responses were excluded from the analysis of reaction times, as were responses faster than $150 \mathrm{~ms}$ or slower than $1500 \mathrm{~ms}(1.18 \%$ of trials $)$.

\section{Words}

\section{--- Insert Table 2 about here ---}

Table 2 shows mean reaction time and error rates for each prime condition. Along with analysis using null hypothesis significance testing, we also provide Bayes Factors (calculated using the BayesFactor R package; Rouder, Morey, Speckman, \& Province, 2012) for the three key comparisons of interest (the evidence of priming for the three prime types), which provides a quantitative measure of evidence for or against the null hypothesis. The main effect of prime condition on RT was statistically significant, $F 1(3,357)=5.09, p=.002 ; F 2(3,222)=4.80, p=$ .003. Specifically, the three related conditions showed significant priming relative to the unrelated condition by subjects, $t 1(119)=4.11, p<.001, B F_{10}=227.98$, and by items, $t 2(74)=3.46, p=.001, B F_{10}=26.9$. However, the mean RT for the affixed conditions did not differ from the non-affixed condition, $t 1(119)=0.99, p=.323, B F_{10}=0.16 ; t 2(74)=1.05, p=$ $.295, B F_{10}=0.22$. Critically, there was no difference between the interpretable and uninterpretable affixed conditions, $t 1(119)=0.25, p=.802, B F_{10}=0.1 ; t 2(74)=0.36, p=.718$, $B F_{10}=0.14$. These non-significant results with Bayes Factors all lower than $\frac{1}{3}$ provide moderate to strong evidence for the null hypothesis of no priming effect (Stefan, Gronau, Schönbrodt, \& 
Wagenmakers, 2019). The analysis of accuracy data showed no effect of prime condition, $F 1(3$, $357)=0.48, p=.694 ; F 2(3,222)=0.49, p=.689$.

\section{--- Insert Figure 2 about here ---}

To check that a possible role of interpretability had not been masked by discretisation of this variable, we examined its continuous effect for the full set of 208 affixed nonword primes. Priming effects (relative to the unrelated condition) were computed for each of the affixed primes. As can be seen in Figure 2, the item-level data showed no indication of any positive relationship between nonword interpretability ratings and priming effects; there was a small, nonsignificant, negative correlation $(r=-0.06, n=208, p=.377)$.

\section{Nonwords}

\section{--- Insert Table 3 about here ---}

Table 3 shows mean reaction time and error rates for nonwords in each prime condition. As can be seen, each of the condition means was within $3 \mathrm{~ms}$ of the grand mean, i.e., there was no difference in mean RT across conditions, $F 1(3,357)=0.44, p=.727 ; F 2(3,291)=0.36, p=$ .779. Similarly, the analysis of accuracy data showed no effect of prime condition, $F 1(3,357)=$ $0.25, p=.860 ; F 2(3,291)=0.20, p=.897$

\section{Discussion}

The main goal of this experiment was to determine whether semantic interpretability influences masked priming for nonword primes, as suggested in a recent article by Heathcote et al. (2017). The results were unambiguous in showing that semantic interpretability had no 
influence on priming: equivalent priming was obtained for the interpretable and uninterpretable prime conditions.

The reader will note that we are in the (not uncommon) position of claiming a null effect of a variable for which an effect has previously claimed. We would address this concern in four ways. First, we believe that it is unlikely that our null effect reflects a lack of statistical power. Our analysis of reaction times for words includes over 2100 observations per prime condition (by contrast, Heathcote et al. (2017)'s experiment had 30 participants and 18 targets per prime condition, giving approximately 500 observations per condition). Secondly, the difference in mean RT between the interpretable and uninterpretable affixed prime conditions was $0.5 \mathrm{~ms}$. Thirdly, Bayes Factors for the critical contrast ( 0.1 by-participants and 0.14 by-items) showed moderate to strong evidence in support of the null hypothesis, where less than 0.3 is considered moderate and less than 0.1 as strong evidence (Stefan et al., 2019). While this level of evidence might not be considered definitive, due to the slow rate of evidence accumulation for a true null as sample size increases (and particularly for default priors; Stefan, Gronau, Schönbrodt, \& Wagenmakers, 2019) much larger sample sizes are necessary for stronger evidence (Brysbaert, 2019). This has led to $<0.33$ being suggested as a reasonable threshold to achieve to support the null hypothesis (Brysbaert, 2019). Finally, Figure 2 and the lack of significant correlation between interpretability and item-level priming suggests that the failure to find an effect of interpretability was not due to the dichotomisation of this variable in the ANOVA.

However, perhaps the most important point to make in this respect is that our null effect does not represent a failure to replicate a significant effect, but rather the inclusion of a critical condition that was not present in Heathcote et al. (2017)'s experiment. The absence of an uninterpretable affixed nonword prime condition from their experiment means that the claim of 
an effect of interpretability rests on a comparison between interpretable affixed nonword primes and non-affixed nonword primes. The difficulty here is that such a comparison may reflect factors other than interpretability, most obviously the difference between affixes and non-affixes (though other uncontrolled factors may also be at work). To be fair to Heathcote et al. (2017), their conclusion was influenced by a body of prior empirical data that has presented a somewhat confusing picture as to whether there is a difference between affixed and non-affixed nonword primes, and the results of their experiment were presented as a possible reconciliation of this confusion.

It could be argued that our findings differ from Heathcote et al's (2017) because we only used suffixed primes. Previous studies have demonstrated differences between how prefixed and suffixed primes are processed (e.g. Beyersmann, Ziegler, \& Grainger, 2015; Kim, Wang, \& Taft, 2015). Therefore, one may suggest that inclusion of prefixed primes would have increased our chances of reporting a semantic transparency effect. However, this still does not provide a sufficient reason of why our results are inconsistent with Heathcote et al (2017) since they found no significant difference in priming between suffixed and prefixed primes.

Indeed, rather than being a failure to replicate, our results are consistent with those of Longtin and Meunier (2005), who found equivalent priming from interpretable (rapidifier$R A P I D E)$ and non-interpretable (sportation-SPORT) nonword primes. Furthermore, finding no effect of semantic interpretability for nonword primes aligns with the general finding of no semantic transparency effects for masked word primes (Rastle \& Davis, 2008).

Another difference between our findings and those of Heathcote et al. (2017) is that we found no difference between affixed and non-affixed nonword primes. Given the equivalence of 
the interpretable and uninterpretable affixed conditions, we can eliminate the possible confound of interpretability (i.e., we found no difference between uninterpretable affixed pairs like maskity$M A S K$ and uninterpretable non-affixed pairs like maskond-MASK). It is not clear why our result differs from Heathcote et al. (2017)'s, but it is consistent with the findings reported in other recent experiments that found equivalent priming for affixed and non-affixed nonword primes (e.g., Beyersmann et al., 2015, 2016; Morris et al., 2011). Then again, as noted earlier, the initial investigations of this issue did find significant differences favouring affixed primes (Longtin \& Meunier, 2005; McCormick et al., 2009), and we observed a numerical difference of $5 \mathrm{~ms}$ in this direction. The present data do not allow us to rule out the possibility that there is a small effect of nonword affixation to be found. Nevertheless, we would reiterate that our experiment was relatively high-powered by comparison with other experiments in this field, which mostly comprise experiments with fewer than 1000 data points per condition, and often fewer than 500 (see Davis \& Rastle, 2010 for relevant funnel plots for experiments with word primes). Brysbaert and Stevens (2018) recommend that at least 1600 observations are required in repeated measures priming experiments that aim to detect effect sizes of around $15 \mathrm{~ms}$. The danger associated with small sample sizes is not only that real effects may not be detected but also that the imprecision of measurement may lead to Type I errors, i.e., the "detection" of effects that are not really present (e.g., Button et al., 2013). A resolution of this empirical uncertainty is forthcoming, as the most recent form priming project (FPP2), which includes approximately 17,000 data points per condition, has compared pseudo-prefixed, pseudo-suffixed and orthographic control conditions. ${ }^{2}$

\footnotetext{
${ }^{2}$ Preliminary results presented by Davis (2018) show no difference between the pseudo-affixed and orthographic control conditions.
} 
We emphasise that our claim is not that semantic transparency is not an important factor, but rather that it does not emerge sufficiently rapidly to influence masked priming. This account agrees with the explanatory framework proposed by Rastle and colleagues based on experiments with word primes (Rastle \& Davis, 2008; Rastle et al., 2000). As noted earlier, Heyer and Kornishova (2018) have recently presented converging evidence on this point, finding no evidence of semantic transparency when the prime duration was $33 \mathrm{~ms}$ or $39 \mathrm{~ms}$, but a significant effect of transparency when the prime was presented for $67 \mathrm{~ms}$ or $77 \mathrm{~ms}$; they also review the extant literature, and note that (with one exception, where methodological differences may have contributed) "significantly stronger priming for transparent in comparison to opaque items emerged only at SOAs of $50 \mathrm{~ms}$ or more" (p. 1121). That is, semantic transparency effects appear when the prime is presented for a duration sufficient to make conscious report possible. That is, semantic transparency effects appear to be restricted to situations in which the prime is presented so briefly that it is not unavailable for conscious report; when primes are perceptible, clear effects of transparency emerge. Whether or not conscious awareness of primes is critical is not clear. It may rather be that primes of $60 \mathrm{~ms}$ duration or more offer sufficient time for a deeper level of semantic processing, or enough time to allow a longer-lasting record of the prime to be established, which can be processed semantically after the offset of the prime. It may take longer for semantic information to become available for novel (interpretable) pseudoword primes than for familiar word primes. Direct comparison of the time-course of semantic transparency and semantic interpretability effects may be an interesting avenue for future experiments.

Ultimately, the question still remains on how corner facilitates (rather than inhibiting) the target CORN and also, why recent masked nonword priming literature, including our study, report no difference in priming between affixed and non-affixed nonword primes. A recent 
proposal by Grainger and Beyersmann (2017) may potentially address both of these questions. They propose that morphological processing is triggered by stem activation. Stem activation is achieved by an edge-aligned stem activation mechanism which takes advantage of the fact stems are either part of the first or last letter of a morphologically complex word. Grainger and Beyersmann (2017) answers the question of why a pseudo-affixed prime such as corner facilitates the target CORN and yet a non-affixed prime like cashew inhibits the target CASH. They argue the prime cashew acts a lexical competitor against the target CASH and thus stem activation is inhibited. In contrast, the presence of the pseudo-affix in corner triggers morpho-orthographic decomposition and in turn, enables stem activation. The edge-aligned stem activation mechanism also addresses why nonword priming studies find no difference in priming between affixed and non-affixed primes. By definition, nonword primes are not contained in the lexicon. Therefore, stem activation is able to be activated regardless of whether the nonword primes are affixed or non-affixed. This is since neither types of nonwords act as lexical competitors against the target.

Recent research appears to support the proposal of an edge-aligned stem activation mechanism. For example, Beyersmann and Grainger (2018) used the masked priming paradigm to investigate whether priming effects are modulated by morphological family size. Morphological family size is the number of different morphologically complex contexts in which a word can appear in. The results suggests morphological family size does indeed influence the size of priming effects where primes with a larger family size results in greater priming. This indicates lexical or supra-lexical representations are involved in activating words embedded in a morphologically complex word which is consistent with Grainger and Beyersmann's (2017) proposal. Another study which supports Grainger and Beyersmann's (2017) proposal is Beyersmann et al. (2018). They compared priming effects between stems which were either edge- 
embedded (e.g. pimebook-BOOK) mid-embedded (e.g. pibookme-BOOK) or outer-embedded (e.g. bopimeok-BOOK) in primes. Priming effects were only found for edge-aligned stems. This indicates activation of embedded words are influenced by edge-alignedness which, again, is in line with Grainger and Beyersmann's (2017) proposal. Considering Beyersmann and Grainger's (2018) and Beyersmann et al's (2018) results, the proposal for an edge-aligned stem activation mechanism, so far, appears to be promising in explaining how morphological processing is implemented.

Overall, the picture that emerges from our experiment with affixed nonword primes is consistent with the larger literature on orthographic form priming. Existing computational models of masked form priming are able to capture these results, despite including no morphological representations (e.g., Adelman, 2011; Davis, 2010, 2018). It may be that results that have been characterised as demonstrating morpho-orthographic decomposition are more parsimoniously characterised as further demonstrations of position-invariant orthographic input coding. This does not undermine the fact that there is something morphological to be explained - in particular, existing orthographic processing models do not explain the pattern observed with pseudo-derived word primes like corner. From the perspective of models such as the spatial coding model (Davis, 2010), the question to be answered is why corner facilitates (rather than inhibiting) the target CORN. Our results help to constrain the set of possible answers by arguing against the possibility that affixes are automatically and inevitably stripped from masked primes. 


\section{Open Practices}

The data from the present experiment are publicly available at the Open Science

Framework website: https://osf.io/7y2ve/ 


\section{References}

Adelman, J. S. (2011). Letters in time and retinotopic space. Psychological Review, $118(4), 570$.

Adelman, J. S., Johnson, R. L., McCormick, S. F., McKague, M., Kinoshita, S., Bowers, J. S., ... Davis, C. J. (2014). A behavioral database for masked form priming. Behavior Research Methods, 46(4), 1052-1067.

Allaire, J., Wickham, H., Ushey, K., \& Ritchie, G. (2017). Rstudioapi: Safely access the rstudio api. Retrieved from https://CRAN.R-project.org/package=rstudioapi

Aust, F., \& Barth, M. (2018). papaja: Create APA manuscripts with R Markdown. Retrieved from https://github.com/crsh/papaja

Bates, D., \& Maechler, M. (2018). Matrix: Sparse and dense matrix classes and methods. Retrieved from https://CRAN.R-project.org/package=Matrix

Beyersmann, E., Casalis, S., Ziegler, J. C., \& Grainger, J. (2015). Language proficiency and morpho-orthographic segmentation. Psychonomic Bulletin \& Review, 22(4), 1054-1061.

Beyersmann, E., Cavalli, E., Casalis, S., \& Colé, P. (2016). Embedded stem priming effects in prefixed and suffixed pseudowords. Scientific Studies of Reading, 20(3), 220-230.

Beyersmann, E., \& Grainger, J. (2018). Support from the morphological family when unembedding the stem. Journal of Experimental Psychology: Learning, Memory, and Cognition, 44(1), 135. 
Beyersmann, E., Kezilas, Y., Coltheart, M., Castles, A., Ziegler, J. C., Taft, M., \& Grainger, J. (2018). Taking the book from the bookshelf: Masked constituent priming effects in compound words and nonwords. Journal of Cognition, 1(1), 10.

Bowers, J. S., Davis, C. J., \& Hanley, D. A. (2005). Automatic semantic activation of embedded words: Is there a "hat" in "that"? Journal of Memory and Language, 52(1), 131-143.

Brysbaert, M. (2019). How many participants do we have to include in properly powered experiments? A tutorial of power analysis with reference tables. Journal of Cognition, 2(1).

Brysbaert, M., \& Stevens, M. (2018). Power analysis and effect size in mixed effects models: A tutorial. Journal of Cognition, 1(1).

Brysbaert, M., McCormick, S. F., Van der Haegen, L., Keuleers, E., \& Davis, C. J. (2015). Masked associative priming in visual word recognition: What matters and what does not. Unpublished Manuscript.

Burani, C., Dovetto, F. M., Spuntarelli, A., \& Thornton, A. M. (1999). Morpholexical access and naming: The semantic interpretability of new root-suffix combinations. Brain and Language, 68(1-2), 333-339.

Button, K. S., Ioannidis, J. P., Mokrysz, C., Nosek, B. A., Flint, J., Robinson, E. S., \& Munafò, M. R. (2013). Power failure: Why small sample size undermines the reliability of neuroscience. Nature Reviews Neuroscience, 14(5), 365.

Coolen, R., Van Jaarsveld, H. J., \& Schreuder, R. (1991). The interpretation of isolated novel nominal compounds. Memory \& Cognition, 19(4), 341-352. 
Crepaldi, D., Hemsworth, L., Davis, C. J., \& Rastle, K. (2016). Masked suffix priming and morpheme positional constraints. The Quarterly Journal of Experimental Psychology, 69(1), $113-128$.

Davis, C. J. (1999). The self-organising lexical acquisition and recognition (solar) model of visual word recognition. ( $\mathrm{PhD}$ thesis). ProQuest Information \& Learning.

Davis, C. J. (2010). The spatial coding model of visual word identification. Psychological Review, 117(3), 713-758. https://doi.org/10.1037/a0019738

Davis, C. J. (2018). Progress in the quest to crack the orthographic code. Paper presented at the Experimental Psychology Society Meeting, London, 5 January, https:/www.youtube.com/watch?v=YDID94rPrWY\&list=PL4GU_32-YTUAs8JFnxi6ys=365.

Davis, C. J., \& Lupker, S. J. (2006). Masked inhibitory priming in English: Evidence for lexical inhibition. Journal of Experimental Psychology: Human Perception and Performance, $32(3), 668$.

Davis, C. J., \& Taft, M. (2005). More words in the neighborhood: Interference in lexical decision due to deletion neighbors. Psychonomic Bulletin \& Review, 12(5), 904-910.

Davis, C. J., Perea, M., \& Acha, J. (2009). Re(de)fining the orthographic neighborhood: The role of addition and deletion neighbors in lexical decision and reading. Journal of Experimental Psychology: Human Perception and Performance, 35(5), 1550.

Davis, M. H., \& Rastle, K. (2010). Form and meaning in early morphological processing: Comment on feldman, o'Connor, and moscoso del prado martín (2009). Psychonomic Bulletin \& Review, 17(5), 749-755. 
De Moor, W., \& Brysbaert, M. (2000). Neighborhood-frequency effects when primes and targets are of different lengths. Psychological Research, 63(2), 159-162.

Diependaele, K., Sandra, D., \& Grainger, J. (2005). Masked cross-modal morphological priming: Unravelling morpho-orthographic and morpho-semantic influences in early word recognition. Language and Cognitive Processes, 20(1-2), 75-114.

Drews, E., \& Zwitserlood, P. (1995). Morphological and orthographic similarity in visual word recognition. Journal of Experimental Psychology: Human Perception and Performance, 21(5), 1098.

Duñabeitia, J. A., Perea, M., \& Carreiras, M. (2007). Do transposed-letter similarity effects occur at a morpheme level? Evidence for morpho-orthographic decomposition. Cognition, 105(3), 691-703.

Feldman, L. B., Milin, P., Cho, K. W., Prado Martín, M. del, F., \& O’Connor, P. A. (2015). Must analysis of meaning follow analysis of form? A time course analysis. Frontiers in Human Neuroscience, 9, 111.

Forster, K. I., \& Forster, J. C. (2003). DMDX: A windows display program with millisecond accuracy. Behavior Research Methods, Instruments, \& Computers, 35(1), 116-124.

Forster, K. I., Davis, C., Schoknecht, C., \& Carter, R. (1987). Masked priming with graphemically related forms: Repetition or partial activation? The Quarterly Journal of Experimental Psychology Section A, 39(2), 211-251. 
Frost, R., Forster, K. I., \& Deutsch, A. (1997). What can we learn from the morphology of hebrew? A masked-priming investigation of morphological representation. Journal of Experimental Psychology: Learning, Memory, and Cognition, 23(4), 829.

Gold, B. T., \& Rastle, K. (2007). Neural correlates of morpho-orthographic decomposition during visual word recognition. Journal of Cognitive Neuroscience.

Grainger, J., Colé, P., \& Segui, J. (1991). Masked morphological priming in visual word recognition. Journal of Memory and Language, 30(3), 370-384.

Grainger, J., Van Heuven, W., \& Bonin, P. (2003). The mental lexicon. P. Bonnin Sous Presse.

Grainger, J., \& Beyersmann, E. (2017). Edge-aligned embedded word activation initiates morpho-orthographic segmentation. In Psychology of Learning and Motivation (Vol. 67, pp. 285317). Academic Press.

Heathcote, L., Nation, K., Castles, A., \& Beyersmann, E. (2017). Do “blacheap” and “subcheap" both prime 'cheap'? An investigation of morphemic status and position in early visual word processing. The Quarterly Journal of Experimental Psychology, 1-34.

Heyer, V., \& Kornishova, D. (2018). Semantic transparency affects morphological priming... eventually. The Quarterly Journal of Experimental Psychology, 71(5):1112-1124

Kazanina, N. (2011). Decomposition of prefixed words in russian. Journal of Experimental Psychology: Learning, Memory, and Cognition, 37(6), 1371. 
Kazanina, N., Dukova-Zheleva, G., Geber, D., Kharlamov, V., \& Tonciulescu, K. (2008). Decomposition into multiple morphemes during lexical access: A masked priming study of Russian nouns. Language and Cognitive Processes, 23(6), 800-823.

Kim, S. Y., Wang, M., \& Taft, M. (2015). Morphological decomposition in the recognition of prefixed and suffixed words: Evidence from Korean. Scientific Studies of Reading, 19, 183-203.

Lawrence, M. A. (2016). Ez: Easy analysis and visualization of factorial experiments. Retrieved from https://CRAN.R-project.org/package=ez

Longtin, C. M., \& Meunier, F. (2005). Morphological decomposition in early visual word processing. Journal of Memory and Language, 53(1), 26-41.

Longtin, C. M., Segui, J., \& Hallé, P. A. (2003). Morphological priming without morphological relationship. Language and Cognitive Processes, 18(3), 313-334.

Lupker, S. J., Zhang, Y. J., Perry, J. R., \& Davis, C. J. (2015). Superset versus substitution-letter priming: An evaluation of open-bigram models. Journal of Experimental Psychology: Human Perception and Performance, 41(1), 138.

Marslen-Wilson, W., Tyler, L. K., Waksler, R., \& Older, L. (1994). Morphology and meaning in the english mental lexicon. Psychological Review, 101(1), 3.

McCormick, S. F., Brysbaert, M., \& Rastle, K. (2009). Short article: Is morphoorthographic decomposition limited to low-frequency words? Quarterly Journal of Experimental Psychology, 62(9), 1706-1715. 
McCormick, S. F., Rastle, K., \& Davis, M. H. (2009). Adore-able not adorable?

Orthographic underspecification studied with masked repetition priming. European Journal of Cognitive Psychology, 21(6), 813-836.

Meunier, F., \& Longtin, C. M. (2007). Morpho-orthographic decomposition and semantic integration in word processing. Journal of Memory and Language, 56(4), 457-471.

Morey, R. D., \& Rouder, J. N. (2018). BayesFactor: Computation of bayes factors for common designs. Retrieved from https://CRAN.R-project.org/package=BayesFactor

Morris, J., Frank, T., Grainger, J., \& Holcomb, P. J. (2007). Semantic transparency and masked morphological priming: An ERP investigation. Psychophysiology, 44(4), 506-521.

Morris, J., Porter, J. H., Grainger, J., \& Holcomb, P. J. (2011). Effects of lexical status and morphological complexity in masked priming: An erp study. Language and Cognitive Processes, 26(4-6), 558-599.

Müller, K. (2018). Bindrcpp: An 'rcpp' interface to active bindings. Retrieved from https://CRAN.R-project.org/package=bindrcpp

Norris, D., Kinoshita, S., \& Casteren, M. van. (2010). A stimulus sampling theory of letter identity and order. Journal of Memory and Language, 62(3), 254-271.

Plummer, M., Best, N., Cowles, K., \& Vines, K. (2006). CODA: Convergence diagnosis and output analysis for mcmc. $R$ News, 6(1), 7-11. Retrieved from https://journal.rproject.org/archive/ 
R Core Team. (2018). R: A language and environment for statistical computing. Vienna, Austria: R Foundation for Statistical Computing. Retrieved from https://www.R-project.org/

Rastle, K., \& Davis, M. H. (2008). Morpho-orthographic decomposition based on the analysis of orthography. Language and Cognitive Processes, 23(7-8), 942-971.

Rastle, K., Davis, M. H., \& New, B. (2004). The broth in my brother's brothel: Morphoorthographic segmentation in visual word recognition. Psychonomic Bulletin \& Review, 11(6), $1090-1098$.

Rastle, K., Davis, M. H., Marslen-Wilson, W. D., \& Tyler, L. K. (2000). Morphological and semantic effects in visual word recognition: A time-course study. Language and Cognitive Processes, 15(4-5), 507-537.

Schreuder, R., \& Baayen, R. H. (1995). Modeling morphological processing. In Morphological aspects of language processing (pp. 131-154). Laurie B. Feldman.

Segui, J., \& Grainger, J. (1990). Priming word recognition with orthographic neighbors: Effects of relative prime-target frequency. Journal of Experimental Psychology: Human Perception and Performance, 16(1), 65.

Stefan, A. M., Gronau, Q. F., Schönbrodt, F. D., \& Wagenmakers, E. J. (2019). A tutorial on Bayes Factor Design Analysis using an informed prior. Behavior Research Methods, 51(3), 1042-1058.

Van Assche, E., \& Grainger, J. (2006). A study of relative-position priming with superset primes. Journal of Experimental Psychology: Learning, Memory, and Cognition, 32(2), 399. 
Welvaert, M., Farioli, F., \& Grainger, J. (2008). Graded effects of number of inserted letters in superset priming. Experimental Psychology, 55(1), 54-63.

Whitney, C. (2001). How the brain encodes the order of letters in a printed word: The seriol model and selective literature review. Psychonomic Bulletin \& Review, 8(2), 221-243.

Wickham, H. (2009). GGplot2: Elegant graphics for data analysis. Springer-Verlag New York. Retrieved from http://ggplot2.org

Wickham, H., Francois, R., Henry, L., \& Müller, K. (2017). Dplyr: A grammar of data manipulation. Retrieved from https://CRAN.R-project.org/package=dplyr

Wurm, L. H. (2000). Auditory processing of polymorphemic pseudowords. Journal of Memory and Language, 42(2), 255-271. 


\section{Figure Captions}

Figure 1. Distributions of mean interpretability ratings for items in the two affixed nonword conditions.

Figure 2. Item level priming effects as a function of mean subjective interpretability for all affixed nonwords. 


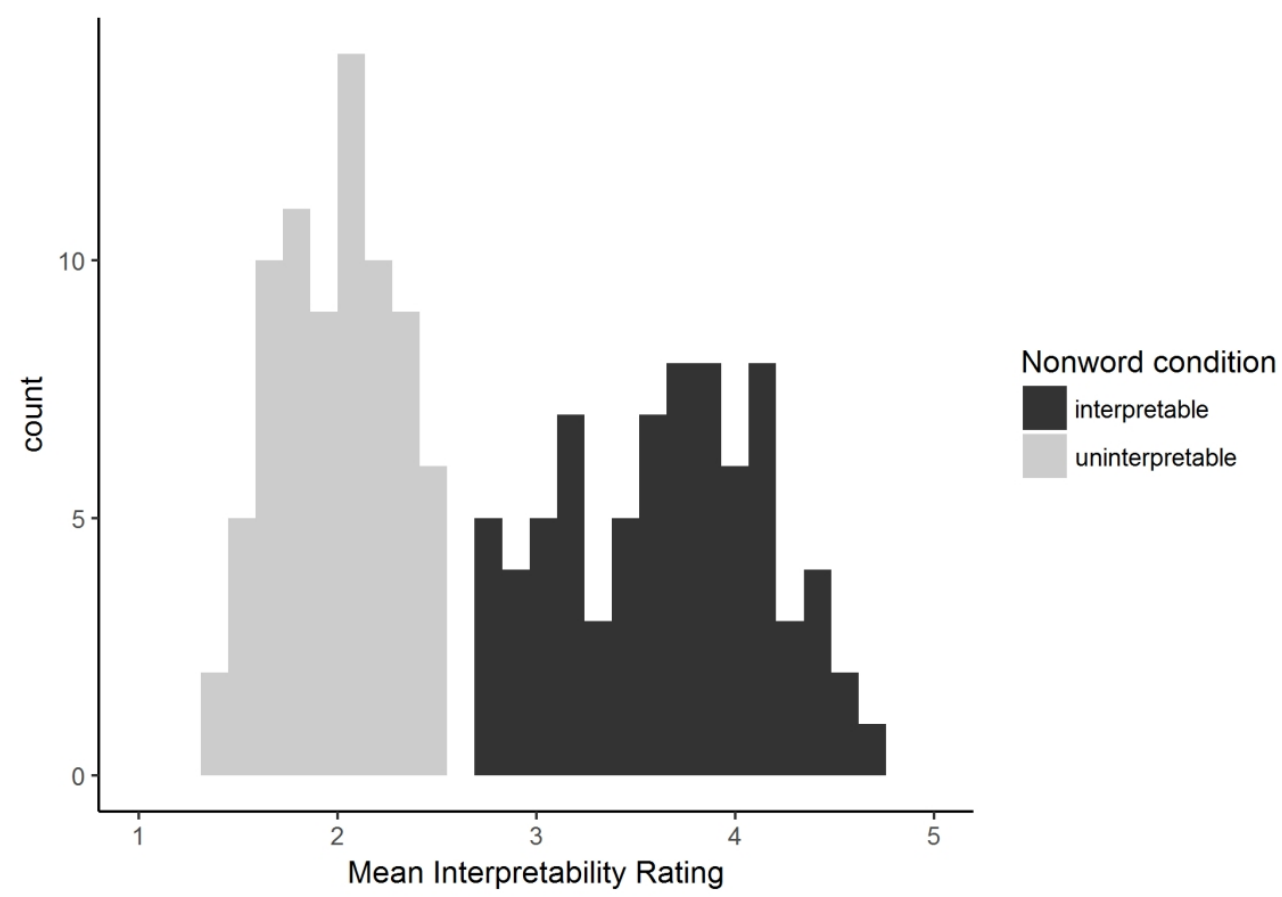

Figure 1: Distributions of Mean Interpretability Ratings For Items In The Two Affixed Nonword Conditions. 




Figure 2: Item-Level Priming Effects As A Function Of Mean Subjective Interpretability For All Affixed Nonwords. 
Table 1

Characteristics of prime stimuli.

\begin{tabular}{|c|c|c|c|c|c|c|c|c|c|}
\hline & & & & & Affix & & & & \\
\hline & & & Length & Affix & Length & & SLBF & & $\mathrm{N}$ \\
\hline Condition & Example & Length & $\mathrm{SD}$ & Length & $\mathrm{SD}$ & SLBF & $\mathrm{SD}$ & $\mathrm{N}$ & $\mathrm{SD}$ \\
\hline Interpretable & maskless & 8.42 & 1.01 & 3.58 & 0.69 & 16.67 & 3.34 & 0.14 & 0.38 \\
\hline & - MASK & & & & & & & & \\
\hline Uninterpretable & maskity & 8.42 & 1.20 & 3.58 & 0.92 & 17.92 & 4.40 & 0.10 & 0.41 \\
\hline & - MASK & & & & & & & & \\
\hline Non-affixed & maskond & 8.44 & 1.02 & 3.60 & 0.51 & 14.97 & 2.90 & 0.01 & 0.10 \\
\hline & - MASK & & & & & & & & \\
\hline Unrelated & tubeful - & 8.38 & 1.04 & 3.54 & 0.67 & 16.76 & 3.24 & 0.19 & 0.59 \\
\hline & MASK & & & & & & & & \\
\hline
\end{tabular}

Note. $\mathrm{SLBF}=\mathrm{Sum}$ Log Bigram Frequency 
Table 2

Mean correct reaction times, standard deviations and standard errors and priming effects in ms, and error rates for target words in each prime condition.

Condition $\quad \mathrm{RT}(\mathrm{ms}) \quad \mathrm{n} \quad \mathrm{SD}$ se Priming ER

\begin{tabular}{lllllll}
\hline Interpretable & 610 & 2128 & 158 & 3.43 & 17 & 0.05
\end{tabular}

$\begin{array}{lllllll}\text { Uninterpretable } & 611 & 2114 & 152 & 3.31 & 16 & 0.05\end{array}$

$\begin{array}{lllllll}\text { Non-affixed } & 615 & 2119 & 156 & 3.39 & 11 & 0.05\end{array}$

$\begin{array}{llllll}\text { Unrelated } & 627 & 2124 & 154 & 3.35 & 0.05\end{array}$

Note. Priming is calculated with respect to unrelated baseline 
Table 3

Mean correct reaction times, standard deviations and standard errors and priming effects in ms, and error rates for target nonwords in each prime condition.

Condition $\quad \mathrm{RT}(\mathrm{ms}) \quad \mathrm{n} \quad \mathrm{SD}$ se Priming ER

\begin{tabular}{lllllll}
\hline Interpretable & 712 & 2626 & 186 & 3.63 & 0 & 0.09
\end{tabular}

$\begin{array}{lllllll}\text { Uninterpretable } & 711 & 2642 & 185 & 3.60 & 1 & 0.09\end{array}$

Non-affixed $\quad \begin{array}{llllll}708 & 2630 & 186 & 3.62 & 4 & 0.09\end{array}$

$\begin{array}{llllll}\text { Unrelated } & 712 & 2644 & 182 & 3.55 & 0.09\end{array}$

Note. Priming is calculated with respect to unrelated baseline 